\title{
The effects of Co addition on the mechanical and microstructural properties of the matrix material of a Fe-based marble cutting tool
}

\author{
S. Budak ${ }^{1}$, M. Kaplan ${ }^{2 *}$ \\ ${ }^{1}$ Department of Electronics and Automation, Gumushane University, 29100, Gumushane, Turkey \\ ${ }^{2}$ Technology Faculty, Department of Metallurgy and Materials Engineering, Firat University, 23119, Elazig, Turkey
}

Received 3 November 2014, received in revised form 21 December 2014, accepted 26 February 2015

\begin{abstract}
In this study, four different kinds of marble cutting matrices with a base composition of $\mathrm{Fe}-\mathrm{Cu}-\mathrm{Sn}$ and with variable amounts of Co powder were produced. For compaction, hot sintering process was carried out at $850^{\circ} \mathrm{C}$ under $35 \mathrm{MPa}$ for $4 \mathrm{~min}$. The mechanical and microstructural properties of the matrix materials were determined using SEM with EDS, three-point bending test, density and hardness measurement techniques. The addition of Co powders to the matrix and the subsequent hot sintering process affected the mechanical and microstructural properties of the cutting tool, such as hardness, total elongation, \% porosity and phase distribution.
\end{abstract}

K e y w or d s: marble cutting tools, cutting matrix material, hot sintering process, mechanical and microstructural properties

\section{Introduction}

Diamond cutting tools manufactured using powder metallurgy are used in a wide variety of applications such as machining of products made out of natural stone, glass, ceramic and metal, highway construction, and boring works. The demand for diamond cutting tools increases day by day. $60 \%$ of these tools and almost all of the marble cutting tools (MCT) are manufactured using the powder metallurgy (PM) technique [1]. In this technique, production of the cutting tool is achieved by mixing diamond particles with metal powders and then compacting by variety of techniques, such as: pressureless sintering [2-6], hot isostatic pressing [7], combination of pressureless sintering and hot isostatic sintering [8], extrusion [9], laser melting [10], combination of hot compaction and laser cutting $[11,12]$ or another specialized technique [13]. The primary factors affecting the cost of cutting tool production are the optimum composition of the materials and selection of other processing parameters. In the production of stonecutters or drilling tools, the manufactured part is composed of approximately $20 \%$ synthetic diamond and $80 \%$ powders made up of various combinations of $\mathrm{Cu}, \mathrm{Sn}$, Fe, Ti, Co, Ni, Al, Mo, CuSn and SiC [14].

Marble cutting or abrasion is mainly performed by the diamond particles in a cutter. Normally, smallsized diamond particles are preferred for the cutting of the hard marbles, e.g. granite and cherry marble, while coarse-sized diamond particles are used for soft marbles. Ideally, the diamond particles should reside in their positions in the metal matrix until they are abraded. In other words, diamond particles and the metal matrix holding these particles should abrade at the same rate. If the matrix abrades later than diamond particles, the diamond particles make poor contact with the marble. In this situation, cutting or abrasion does not occur and the surface of the cutting tool heats up and burns. In the case of rapid abrasion of the matrix material, diamond particles separate from their positions and fall without cutting. For this reason, together with the cutting parameters and properties of the stone to be cut, full control of the properties of the matrix material and the cutting tool is very important [15-17].

\footnotetext{
*Corresponding author: tel.: +90 424 2370000/4259; fax: +90 424 2367064; e-mail address: mkaplan@firat.edu.tr
} 
Table 1. Chemical composition of the specimens

\begin{tabular}{lllll}
\hline & \multicolumn{4}{c}{ Elements (wt.\%) } \\
\cline { 2 - 5 } Specimens & Fe & Cu & Sn & Co \\
\hline S1 & 78 & 20 & 2 & - \\
S2 & 68 & 20 & 2 & 10 \\
S3 & 63 & 20 & 2 & 15 \\
S4 & 58 & 20 & 2 & 20 \\
\hline
\end{tabular}

\section{Experimental study}

\subsection{Fabrication of cutting matrix material}

Hot sintering produced matrix materials with different Co content for use in experimental studies. Table 1 presents chemical composition of the materials. In the production of specimens, $\mathrm{Fe}, \mathrm{Cu}, \mathrm{Co}$ and $\mathrm{Sn}$ powders with $99.9 \%$ purity and particle sizes between 1.1 and $200 \mu \mathrm{m}$ were used. Co-free reference sample S1 produced using $\mathrm{Fe}, \mathrm{Cu}$, and $\mathrm{Sn}$, was produced before the other matrix materials $(\mathrm{S} 2, \mathrm{~S} 3, \mathrm{~S} 4)$.

For production, as-received raw powders were weighed by a balance with $10^{-5} \mathrm{~g}$ sensitivity in the proportions given in Table 1. The uniform mixing of these powders was achieved by using a $2 \mathrm{~kg}$ capacity tubular mixer having two closed chambers and capable of shaking in three dimensions. The first stage of the mixing involved mixing of powders in suitable containers for $15 \mathrm{~min}$ at a rate of $20 \mathrm{rpm}$. In the second stage, Cr-coated steel balls ( $8 \mathrm{~mm}$ in diameter) and $1 \%$ polyethylene glycol (PEG) were added to the containers and samples were mixed for a further $30 \mathrm{~min}$ at $20 \mathrm{rpm}$.

After the mixing stage, powder mixtures were poured into molds made out of graphite plates, the tops of which were covered by top compaction graphite. Graphite molds were put into a steel container and tightened smoothly with compression pins. To control the variation in temperature, the thermocouple was mounted on the mold such that the tip of the thermocouple was positioned at the center of the mold. The whole set-up was then subjected to hot compaction under a protective atmosphere. Starting from $5 \mathrm{MPa}$, samples were hot compacted at constant temperature and pressure $\left(35 \mathrm{MPa}\right.$ at $\left.850^{\circ} \mathrm{C}\right)$ for four minutes. Then, the heating unit was turned off, and samples were allowed to cool to room temperature under $35 \mathrm{MPa}$ pressure.

\subsection{Characterization of the cutting matrix material}

The fabricated cutting matrix materials were characterized by density, hardness, three-point bending

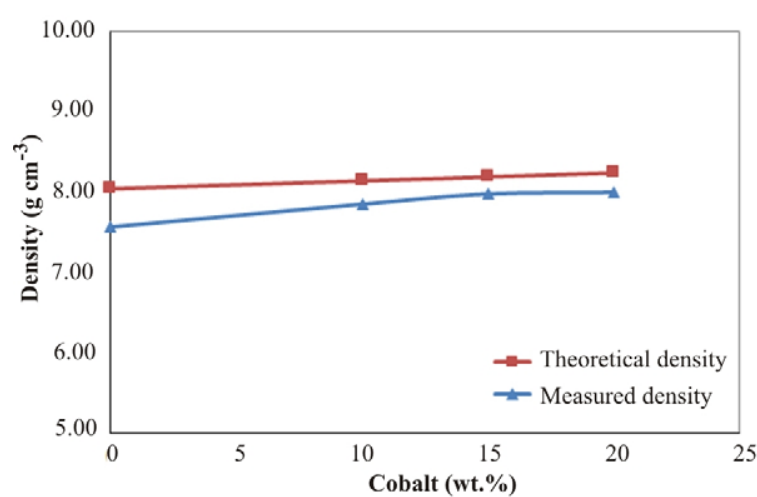

Fig. 1. The effect of Co content on the theoretical and measured values of density.

test and microstructural properties. The density of the matrix materials was measured according to ASTM B311-92 standard, which relies on Archimedes' principle. The Brinell hardness of the samples was measured by using balls with $2.5 \mathrm{~mm}$ diameter and $62.5 \mathrm{~kg}$ of the load; the average of eight measurements was taken as the hardness value. The tensile strength values of the cutting tool matrix materials produced in this study were not measured by standard tensile testing specimens as the samples were much smaller than what is described in the standard. Instead, a three-point bending test was applied to find the strength values. Bending strength values of the samples were measured by a universal test machine, which is suitable to ASTM B 528-83 standard, and TRAPEZIUM X software [17].

For microstructural examination, the surfaces of the samples were smoothed with emery paper, polished and cleaned with pure alcohol. Polished surfaces were etched by an etchant mixture $\left(\mathrm{HNO}_{3}\right.$ with alcohol) so as to create visual differences between different phases. Finally, microstructural examinations were conducted by using an FE-SEM with EDS analyzer (JEOL JSM $7001 \mathrm{~F})$.

\section{Results and discussion}

Mechanical and microstructural properties of the matrix materials were determined using different techniques including SEM, EDS analysis, three-point bending test, density and hardness measurement techniques.

\subsection{Density}

The density measurement of samples with different amounts of Co was performed by using Archimedes' principle. Then, the experimental values were compared with the theoretical values (Table 2 and Fig. 1). 
Table 2. The theoretical and measured density values of cutting matrix material samples

\begin{tabular}{cccc}
\hline Specimens & Measured density $\left(\mathrm{g} \mathrm{cm}^{-3}\right)$ & Theoretical density $\left(\mathrm{g} \mathrm{cm}^{-3}\right)$ & Density $(\%)$ \\
\hline S1 & 7.57 & 8.05 & 94.09 \\
S2 & 7.85 & 8.14 & 96.45 \\
S3 & 7.98 & 8.19 & 97.42 \\
S4 & 8.00 & 8.24 & 97.07 \\
\hline
\end{tabular}

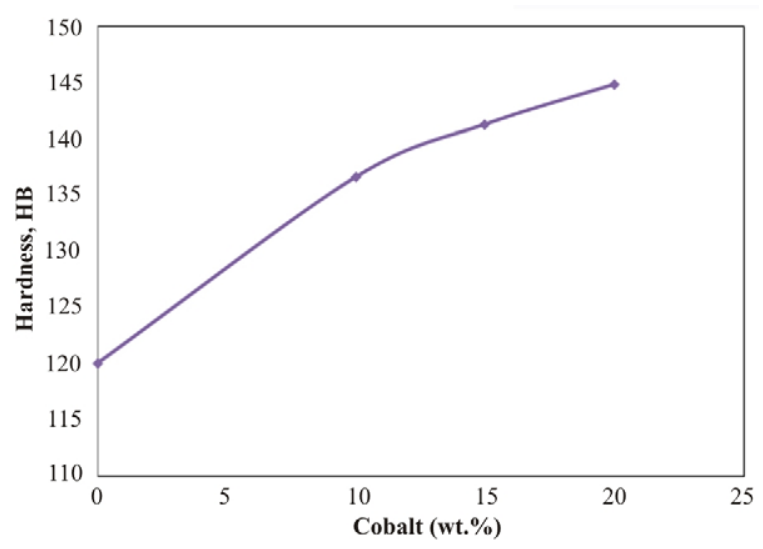

Fig. 2. The variation of hardness value with Co content.

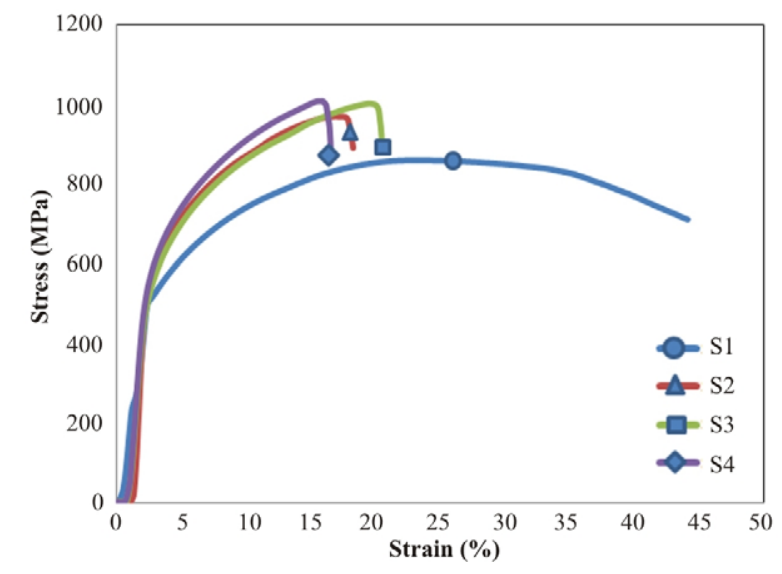

Fig. 3. Results of the three-point bending test for the specimens examined in the study.

As depicted in Fig. 1, the measured densities of the as-sintered samples are quite close to the theoretical values. The coherence between the density values can be considered as an indication of the effectiveness of the sintering process. The difference between theoretical and experimental values of the density is an indication of the level of the porosity in the samples. According to this, samples having the least amount of porosity were $\mathrm{S} 3$ and $\mathrm{S} 4$, with Co content 15-20\%. On the other hand, sample S1 (Co-free) had the highest level of porosity among all samples examined.

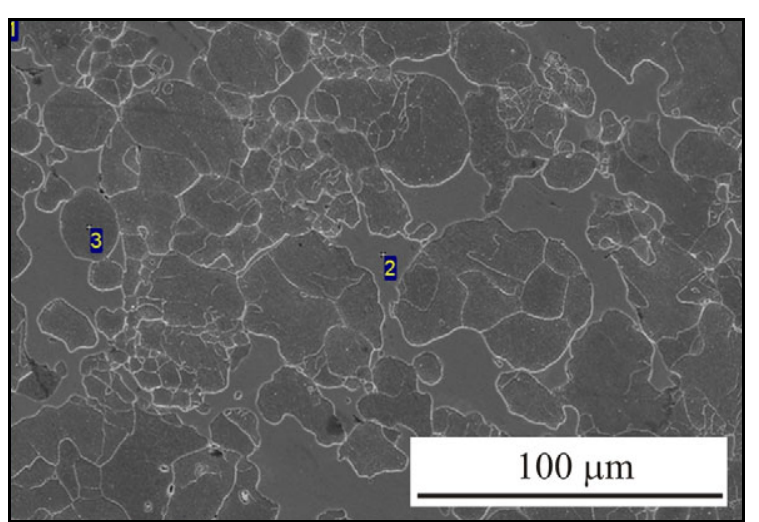

Fig. 4. SEM picture of sample $\mathrm{S} 1$ and the results of the EDS analyses. The magnification is $500 \times$.

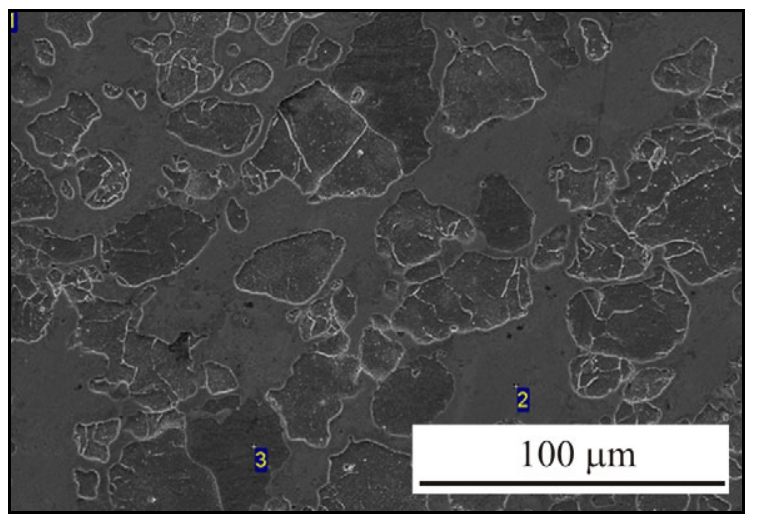

Fig. 5. SEM picture of sample $\mathrm{S} 2$ and the results of the EDS analyses. The magnification is $500 \times$.

\subsection{The results of hardness and bending tests}

The hardness values of the samples are shown in Fig. 2. It can be clearly seen that the hardness values of the samples are increased linearly with the Co content. For example, while the hardness value of the Co-free sample S1 was measured as $120 \mathrm{HB}$, it was found as $145 \mathrm{HB}$ for sample S4 (20\% Co).

The stress-strain curves of samples obtained from three-point bending test are shown in Fig. 3. The Co-free sample S1 possessed nearly $45 \%$ elongation with a bending strength value of $850 \mathrm{MPa}$. Meanwhile, if the stress-strain graph of Co-free sample $\mathrm{S} 1$ is compared with that of Co-containing samples S2, S3, 


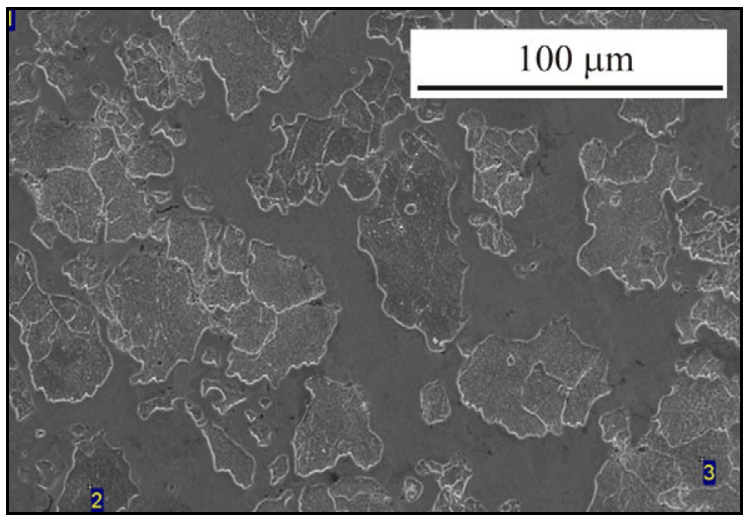

Fig. 6. SEM picture of sample S3 and the results of the EDS analyses. The magnification is $500 \times$.

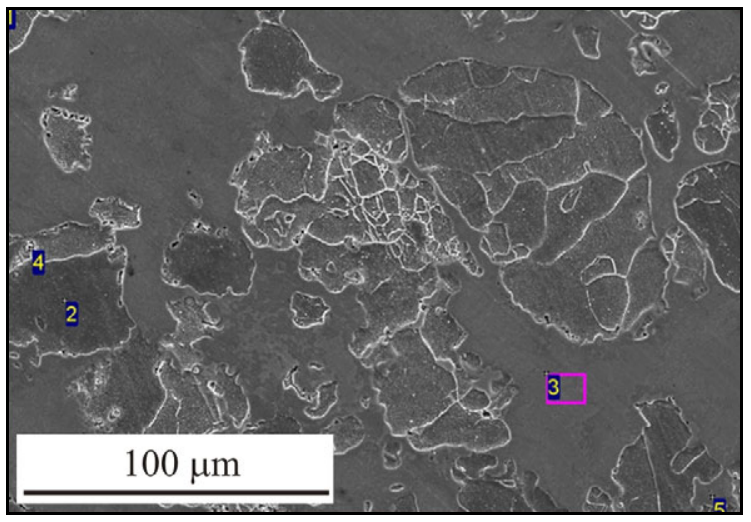

Fig. 7. SEM picture of sample $\mathrm{S} 4$ and the results of the EDS analyses. The magnification is $500 \times$.

and $\mathrm{S} 4$, it can be clearly seen that with the addition of Co, percentual elongation decreased, while bending strength increased. Based on these results, it can be stated that the addition of Co and the sintering process led to a good level of homogeneity and an optimum value of strength. Apart from this, it is already known that the presence of $\mathrm{Cu}$ and $\mathrm{Sn}$ in the matrix is responsible for the high ductility and strength of these systems [18].

\subsection{Microstructure of the alloys}

SEM pictures of samples are given in Figs. 4, 5, 6 and 7, respectively. These figures also include the results of the EDS analyses for the numbered points designated in the pictures. The dominant phases for these points are also mentioned.

According to EDS analyses of the points indicated on the picture of sample S1, the microstructure was mainly composed of $\alpha \mathrm{Fe}+\beta \mathrm{Cu}$. According to the literature, dark regions are $\alpha \mathrm{Fe}$, and bright regions are $\alpha \mathrm{Fe}+\beta \mathrm{Cu}$ [19]. In Fig. 5, which shows the SEM picture of sample S2, it can be seen that Co-
Ta b le 3. Semi-quantitative EDS results for the label 1-3 (S1), in Fig. 4

\begin{tabular}{lrrl}
\hline Element & Weight $(\%)$ & Atomic (\%) & Phase \\
\hline Label 1 & & & \\
C K & 1.96 & 8.85 & \\
Fe K & 72.56 & 70.27 & $\alpha \mathrm{Fe}+\beta \mathrm{Cu}$ \\
Cu K & 23.43 & 19.95 & \\
Sn L & 2.05 & 0.93 & \\
\hline Total & 100.00 & & \\
\hline Label 2 & & & \\
C K & 2.27 & 11.23 & \\
Fe K & 5.58 & 5.93 & \\
Cu K & 84.67 & 79.10 & \\
Sn L & 7.48 & 3.74 & \\
\hline Total & 100.00 & & \\
\hline Label 3 & & & \\
C K & 1.80 & 7.86 & \\
Fe K & 97.34 & 91.43 & \\
Cu K & 0.86 & 0.71 & \\
\hline Total & 100.00 & & \\
\hline
\end{tabular}

Ta ble 4. Semi-quantitative EDS results for the label 1-3 (S2), in Fig. 5

\begin{tabular}{lrrr}
\hline Element & Weight $(\%)$ & Atomic $(\%)$ & Phase \\
\hline Label 1 & & & \\
C K & 2.13 & 9.58 & \\
Fe K & 62.74 & 60.58 & $\alpha \mathrm{Fe}+\mathrm{CuSnCo}$ \\
Co K & 11.36 & 10.39 & \\
Cu K & 21.91 & 18.59 & \\
Sn L & 1.87 & 0.85 & \\
\hline Total & 100.00 & & \\
\hline Label 2 & & & \\
Fe K & 1.92 & 2.21 & \\
Co K & 4.22 & 4.62 & $\mathrm{CuSnCo}+\mathrm{Fe}$ \\
Cu K & 89.45 & 90.77 & \\
Sn L & 4.41 & 2.40 & \\
\hline Total & 100.00 & & \\
\hline Label 3 & & & \\
Fe K & 99.43 & 99.50 & $\mathrm{Fu}$ \\
Cu K & 0.57 & 0.50 & \\
\hline Total & 100.00 & & \\
\hline
\end{tabular}

containing regions appeared with the addition of Co. If the SEM pictures of samples S2 and S1 are compared, it is apparent that the sample $\mathrm{S} 2$ has less amount of 
Ta b le 5. Semi-quantitative EDS results for the label 1-3 (S3), in Fig. 6

\begin{tabular}{lrrr}
\hline Element & Weight (\%) & Atomic (\%) & Phase \\
\hline Label 1 & & & \\
C K & 2.04 & 9.16 & $\alpha \mathrm{Co}, \alpha \mathrm{Fe}+\mathrm{Cu}$ \\
Fe K & 62.79 & 60.55 & \\
Co K & 18.00 & 16.45 & \\
Cu K & 15.37 & 13.03 & \\
Sn L & 1.80 & 0.82 & \\
\hline Total & 100.00 & & $\alpha \mathrm{Fe}+\mathrm{Cu}$ \\
\hline Label 2 & & & \\
Fe K & 99.46 & 99.53 & \\
Cu K & 0.54 & 0.47 & \\
\hline Total & 100.00 & & \\
\hline Label 3 & & & \\
Fe K & 99.62 & 99.67 & $\mathrm{Cu}$ \\
Cu K & 0.38 & 0.33 & \\
\hline Total & 100.00 & & \\
\hline
\end{tabular}

Ta b le 6. Semi-quantitative EDS results for the label 1-3 (S4), in Fig. 7

\begin{tabular}{lrrr}
\hline Element & Weight (\%) & Atomic (\%) & Phase \\
\hline Label 1 & & & \\
C K & 1.92 & 8.73 & \\
Fe K & 55.32 & 53.99 & $\alpha \mathrm{Fe}, \alpha \mathrm{Co}, \mathrm{CuSn}$ \\
Co K & 21.24 & 19.64 & \\
Cu K & 19.46 & 16.69 & \\
Sn L & 2.05 & 0.94 & \\
\hline Total & 100.00 & & \\
\hline Label 2 & & & \\
Fe K & 99.66 & 99.70 & \\
Cu K & 0.34 & 0.30 & \\
\hline Total & 100.00 & & \\
\hline Label 3 & & & \\
C K & 1.99 & 10.01 & \\
Fe K & 6.08 & 6.60 & \\
Co K & 2.93 & 3.01 & CuSn, FeCo \\
Cu K & 78.91 & 75.23 & \\
Sn L & 10.09 & 5.15 & \\
\hline Total & 100.00 & & \\
\hline
\end{tabular}

porosity, appearing black in color.

It is apparent from the SEM pictures and EDS analyses that 10, 15 and $20 \%$ of Co were uniformly mixed in the main matrix of the samples S2, S3, S4, respectively, which were composed primarily of $\mathrm{Fe}$ based $\mathrm{CuSn}$ and $\mathrm{CoSn}$ compounds as well as $\alpha \mathrm{Co}$ $+\beta \mathrm{Cu}$ [19]. Judging by the SEM pictures and EDS analyses of the samples, the $\mathrm{Fe}, \mathrm{Cu}, \mathrm{Sn}$ and $\mathrm{Co}-$ based phases and compounds forming the matrix were homogeneously distributed in the microstructure.

The homogeneous phase distribution in the samples indicates that the two-stage mixing operation performed before the sintering process was sufficient for the homogeneous distribution of the metal powders. It is considered that the sintering process performed at $850^{\circ} \mathrm{C}$ is sufficient for homogeneous mixing of Co and $\mathrm{Cu}$ powders in solid state. It shows that the selected sintering temperature and duration were sufficient for the process. Phase separation between the $2 \%$ Sn present and the rest of the matrix did not occur during sintering, although the melting point of $\mathrm{Sn}$ is about $232{ }^{\circ} \mathrm{C}$. The reason behind this is that according to the Co-Sn equilibrium phase diagram, a stable phase forms between $\alpha \mathrm{Co}$ and Sn at $500-1121^{\circ} \mathrm{C}$ [19]. Taken altogether, SEM and EDS analyses showed that homogeneous matrix structures were obtained in marble cutting tool samples made out of $\mathrm{Fe}-\mathrm{Cu}-\mathrm{Co}-\mathrm{Sn}$ quaternary compounds.

\section{Conclusions}

A marble cutting-tool matrix material made out of $\mathrm{Fe}, \mathrm{Cu}$ and $\mathrm{Sn}$ was produced with the addition of 10,15 or $20 \%$ Co and using hot sintering process. Together with the microstructural examination conducted by SEM and EDS, hardness, density values, and three-point bending properties of the samples were determined. The following conclusions have been reached:

1. With the addition of Co to the cutting tool material $\mathrm{Fe}-\mathrm{Cu}-\mathrm{Sn}$ powder mixture, the density value of the tool material increased. The Co-free sample S1 had the lowest density value among all samples examined, while samples S3 and S4 with Co contents of 15 and $20 \%$, respectively, had the highest density values.

2. Co addition increased the hardness value of the alloy.

3. The addition of Co to the material also increased the tensile strength while decreasing the $\%$ elongation.

4. SEM and EDS analyses show that hot compaction sintering performed at $850^{\circ} \mathrm{C}$ for $4 \mathrm{~min}$. was sufficient to obtain a homogeneous distribution of phases in the microstructure. For these reasons, this alloy, which was produced from metal powders, has sufficient qualifications to be proposed as a marble cutting-tool matrix material.

\section{Acknowledgements}

This work was supported by Scientific Research Projects 
Coordination Unit of Firat University (FÜBAP) with project number 1913, which is gratefully acknowledged.

\section{References}

[1] Przyklenk, K.: Industrial Diamond Review, 53, 1993, p. 192.

[2] Burgess, R. R.: Man-made Diamond for Stone Processing. GE Publication No: SMD, p. 89.

[3] Thakur, U. N.: Industrial Diamond Review, 45, 1985, p. 22.

[4] Dwan, J. D.: Powder Metallurgy, 41, 1998, p. 84. doi:10.1179/pom.1998.41.2.84

[5] Hamar-Thibault, S., Allibert, C. H.: Journal of Alloys and Compounds, 317-318, 2001, p. 363. doi:10.1016/S0925-8388(00)01439-0

[6] Gasik, M. K., Kervinen, P., Kaskiala, M., Graf, P.: Metal Powder Report, 55, 2000, p. 50. doi:10.1016/0026-0657(00)93200-4

[7] Downing, M.: A New Powder Encapsulation Method and its Implication on Densification by Hot Isostatic Pressing. [Ph.D. Thesis]. Bedford, Cranfield Institute of Technology, School of Industrial and Manufacturing Science 1993.

[8] Del Villar, M., Muro, P., Sanchez, J. M., Iturriza, I., Castro, F.: Powder Metallurgy, 1, 2001, p. 82. doi:10.1179/003258901666211

[9] Manukyan, V.: Metal Powder Report, 50, 1995, p. 35. doi:10.1016/0026-0657(95)91342-4

[10] Grüneis, H., Grüneis, T.: Industrial Diamond Review, 45-47, 1998, p. 45.
[11] Konstanty, J.: In: Advances in Powder Metallurgy \& Particulate Materials. Volume 2. Part 5. Eds.: Cadle, T. M., Narasimhan, K. S. Princeton, Metal Powder Industries Federation 1996, p. 3.

[12] Konstanty, J.: Powder Metallurgy Diamond Tools. Oxford, Elsevier 2005.

[13] Çelik, E.: Alternative Binders for Diamond Cutting Tools. [Ph.D. Thesis]. Elazig, Firat University, Graduate School of Natural and Applied Sciences 2009.

[14] Tillmann, W.: International Journal of Refractory Metals \& Hard Materials, 18, 2000, p. 301. doi:10.1016/S0263-4368(00)00034-2

[15] Bayram, F.: [M.Sc. Thesis]. Ankara, Hacettepe University, Graduate School of Natural and Applied Sciences 2002.

[16] Kulaksız, S., Özçelik, Y., Bayram, F., Yaıtlı, N. E., Atasoy, K.: Investigation of Sawing Efficiency on Diamond Segmented Gangsaws. Project No. 0101 602 024. Ankara, Hacettepe University, The Scientific Researches Unit 2002

[17] Primavori, P.: Marmomacchine Directory. Milano, Associazione Italiana Marmomacchine 2002, p. 40.

[18] Ünlü, B. S., Atik, E., Çöllü, C.: Celal Bayar University Soma Vocational School, the Journal of Technical Sciences, 2, 2006, p. 1.

[19] ASM Metals Handbook: Alloy Phase Diagrams. Volume 3. Materials Park, ASM International 1992. 